\title{
Apomorphine for Parkinson's Disease: Efficacy and Safety of Current and New Formulations
}

\author{
Federico Carbone $^{1} \cdot$ Atbin Djamshidian $^{1} \cdot$ Klaus Seppi $^{1} \cdot$ Werner Poewe $^{1}$
}

Published online: 31 August 2019

(c) The Author(s) 2019

\begin{abstract}
Satisfactory management of Parkinson's disease is a challenge that requires a tailored approach for each individual. In the advanced phase of the disease, patients may experience motor complications despite optimized pharmacological therapy. Apomorphine, a short-acting $\mathrm{D}_{1^{-}}$and $\mathrm{D}_{2}$-like receptor agonist, is the only drug proven to have an efficacy equal to that of levodopa, albeit with a shorter time to onset and effect duration. Clinical trials have shown that intermittent apomorphine injections provide rapid and effective relief from unpredictable "off" periods. Continuous apomorphine infusion reduced around 50\% of the daily "off" time in several studies. Dopaminergic side effects such as nausea, somnolence and hypotonia, as well as administration site reactions, are often mild or treatable, but somnolence and skin reactions in particular can sometimes be reasons for premature discontinuation. We provide an overview of the pharmacological mechanism of action of the drug in light of its effects on Parkinson's disease symptoms. We then summarize the evidence regarding the efficacy and tolerability of apomorphine, both in its established formulations (subcutaneous intermittent injection and continuous infusion) and in the new preparations currently under investigation.
\end{abstract}

\section{Key Points}

Apomorphine is the oldest dopaminergic drug available for Parkinson's disease, and-to date-it remains the only drug with efficacy comparable to that of levodopa.

Subcutaneous apomorphine, delivered as a continuous infusion or as intermittent injections, has proven welltolerated and effective.

Several alternative routes to simplify delivery of the drug have been tested, and some are in active clinical development.
Werner Poewe

werner.poewe@i-med.ac.at

1 Department of Neurology, Innsbruck Medical University, Anichstraße 35, 6020 Innsbruck, Austria

\section{Introduction}

Parkinson's disease (PD) is the second most frequent neurodegenerative disease, affecting $1 \%$ of the population aged $>60$ years and reaching 3\% in the highest age groups $[1,2]$. Neuropathological hallmarks are progressive loss of dopaminergic neurons in the pars compacta of the substantia nigra, causing striatal dopamine deficiency, and intracellular inclusions containing aggregates of alpha-synuclein. PD is clinically defined by the presence of bradykinesia and at least one additional cardinal motor feature (rigidity or rest tremor). In addition, most patients with PD also experience non-motor symptoms (NMS), adding to the overall burden of parkinsonian morbidity [2].

PD was the first neurodegenerative disease for which highly efficacious treatments became available. Dopamine replacement with oral levodopa is still the gold standard of symptomatic therapy, matched only by apomorphine in its effect size on motor symptoms [3]. The response to levodopa is maintained in the long term, but many patients develop challenging motor complications such as motor fluctuations and dyskinesia as the disease progresses $[4,5]$. The current role of apomorphine in the treatment of PD is in the management of levodopa-related motor complications-as either intermittent subcutaneous pen injections or continuous 
subcutaneous mini-pump delivery. We review the pharmacology and clinical studies of the efficacy and safety of subcutaneous apomorphine administration in treating motor fluctuations in PD and give a brief overview of alternative apomorphine formulations currently in clinical development.

\section{History of the Molecule Across the Centuries}

Today, apomorphine is known as a dopamine agonist for the treatment of advanced PD, but its first use very likely dates to ancient civilizations, with fascinating analogies between cultures as far apart as those of the Mayas and the ancient Egyptians. Abundant clues rest in the iconography of these two civilizations testifying to the central role of Nymphaea plants (water lilies) in magical-religious rites. We know today that several aporphines, including apomorphine, can be isolated in the roots and bulbs of water lilies. The plants were most likely used as an emetic in purifying rituals and as an aphrodisiac and hallucinogenic for the higher castes [6-8]. Interestingly, the effects sought and experienced by these ancient civilizations are the very same that were clinically assessed thousands of years later, after the discovery of synthetic apomorphine.

The credit for discovering apomorphine is given to the studies of Matthiessen and Wright [9], who in 1868 synthetized apomorphine hydrochloride by heating morphine with concentrated hydrochloric acid. The compound was named apomorphia to highlight its origin and its difference from the mother compound, morphine. While it was only after the experiments by Matthiessen and Wright that apomorphine started to attract interest in both human and veterinary medicine, it is fair to note that Arppe [10] was probably the first to synthetize the molecule in 1845 by heating morphine with an excess of sulphuric acid, therefore naming it sulphomorphide.

In the years following its discovery, apomorphine was used in different experiments in animals and humans, showing a range of effects leading to its use in several fields of medicine. By virtue of the studies conducted by Gee, Hare, Pierce, Siebert and Harnack [11-15] in humans and animals, the effects of apomorphine were linked to action on the central nervous system. Most notably, an emetic response was almost invariably observed in humans and dogs with oral and parenteral administrations. An unwanted effect of today's use of apomorphine, emesis became the main indication for the drug for several decades and led to its use in removing foreign objects from the esophagus or in treating poisoning. This emetic response was also used to induce adverse conditioning by administering the drug with the undesired stimulus in cases of drug, alcohol and smoking dependence [16].
Oral apomorphine is subject to extensive first-pass metabolism resulting in low bioavailability, and parenteral delivery of the drug was the preferred administration route in most studies and experiments $[17,18]$. The clinical use of apomorphine between the end of the nineteenth century and beginning of the twentieth century covered almost every field of medicine. The sedative effects of the drug were employed in a variety of psychiatric conditions, such as mania, hysteria, schizophrenic excitement, anxiety, dementia and, most importantly, alcohol-related disorders [19]. In these studies, spontaneous erection was noted as an unexpected effect, which would much later lead to the commercialization of apomorphine as an agent to treat erectile dysfunction [20].

It was Weil, in 1884, who first hypothesized that apomorphine could be useful in patients with PD, but without any specific rationale [21]. This was still lacking when sub-emetic doses (0.6-0.9 mg subcutaneously) of apomorphine were finally tried in patients with PD by the American neurologist Schwab and colleagues [22] almost 70 years later. These authors noted marked improvement in rigidity and tremor lasting from 1 to $6 \mathrm{~h}$ with enhanced feeling of subjective wellbeing once the initial side effects of nausea and hypotension had resolved. The marked anti-tremor effects of subcutaneous or intramuscular single-dose injections of apomorphine were confirmed shortly after by the German neurologists Struppler and Von Uexkull [23]. However, the peripheral adverse effects and the need for parenteral administration of apomorphine led to its limited use in clinical practice after these early observations on its antiparkinsonian efficacy. About a decade later, the miraculous efficacy of oral levodopa in PD was discovered, and this superseded all interest in apomorphine [24, 25]. Nevertheless, Cotzias-one of the fathers of levodopa therapy for PD-continued to pursue the drug as an agent to treat PD and described the potent antiparkinsonian effects of subcutaneous apomorphine in 15 patients, albeit with marked emetic side effects in a proportion of subjects [26]. In 1979, Corsini et al. [27] showed that nausea deriving from apomorphine injections could be controlled via the administration of domperidone, a peripheral dopamine antagonist that does not cross the blood-brain barrier. This opened the door for successful introduction into clinical practice pioneered by Stibe et al. [28] in London in the mid-1980s. These researchers were able to show the remarkable efficacy of intermittent subcutaneous injections and continuous infusion of apomorphine in reducing the "off" periods in patients with advanced PD [28]. Over the following years, multiple studies confirmed their findings, leading to the approval of apomorphine as an adjunct therapy to reduce "off" time in advanced PD. 


\section{Pharmacological Properties}

Apomorphine is an aporphine alkaloid derived from acidification of morphine. Its molecular formula is $\mathrm{C} 17 \mathrm{H} 17 \mathrm{NO}_{2}$. Its structure, consisting of a tetracycline aporphine ring, is responsible for the lipophilicity and the affinity to dopaminergic receptors. Specifically, the structural similarity to dopamine is conferred by the ortho-catechol group [29]. Like many antipsychotic drugs, apomorphine also possesses a piperidine moiety. Apomorphine is often described as a dopamine agonist, but it has some differences from other oral dopamine agonists used in PD. Thanks to its catechol moiety, apomorphine acts as a potent dopamine receptor agonist with a broad spectrum on all $\mathrm{D}_{1^{-}}$and $\mathrm{D}_{2}$-like receptors $\left(\mathrm{D}_{1}, \mathrm{D}_{2 \mathrm{~S}}, \mathrm{D}_{2 \mathrm{~L}}, \mathrm{D}_{3}, \mathrm{D}_{4}, \mathrm{D}_{5}\right)$ [30]. In comparison, the oral dopamine agonists ropinirole and pramipexole mainly bind to $D_{2}$ and $D_{3}$ receptors without significant affinity to $D_{1}$ receptors [31]. Apomorphine's mode of action is therefore more like that of dopamine or its precursor levodopa. In addition, apomorphine has antagonist properties on serotonergic 5HT2A, 5HT2B and 5HT2C and adrenergic $\alpha 2 \mathrm{~A}, \alpha 2 \mathrm{~B}$ and $\alpha 2 \mathrm{C}$ receptors and agonist properties at serotonergic 5HT1A receptors [32]. Unlike its mother compound, morphine, apomorphine has no affinity for opioid receptors [33].

Apomorphine has very limited oral bioavailability $(<4 \%)$ [34] because of almost complete first-pass hepatic metabolism where the molecule is metabolized following different pathways, including sulfation, glucuronidation and catecholO-methylation. Therefore, different parenteral administration routes have been applied in clinical experiments. As a licensed treatment for PD, apomorphine is currently administered via subcutaneous injections or infusions. The drug absorption (bioavailability 100\%), volume of distribution, plasma clearance and half-lives $\left(t^{1 / 2}\right)$ of subcutaneous injections or infusions are comparable to those of intravenous infusion [35]. However, the latter is not suitable for chronic use because of the possible crystallization of apomorphine in the catheter, leading to the formation of thrombi [36]. Several factors can influence the subcutaneous absorption of the drug: injection site (abdominal injection seems to have the best results), state of the skin (vascularization, skin temperature, body fat), volume and depth of injection [a greater volume leads to a greater area of subcutaneous absorption and influences the time to peak concentration $\left.\left(t_{\max }\right)\right]$ and the presence of subcutaneous nodules that may hinder absorption, both mechanically and via inflammation-related alteration of the blood flow $[35,37,38]$. After subcutaneous injection, peak concentration in the blood $\left(C_{\max }\right)$ is reached in around $10 \mathrm{~min}$, with a maximum concentration in the cerebrospinal fluid achieved after $30 \mathrm{~min}$ [35].

Apomorphine is extremely lipophilic so it has a considerable volume of distribution and, unlike levodopa, can cross the blood-brain barrier freely. Additionally, it seems to concentrate in the brain, reaching a brain-to-blood concentration ratio of 8:1 [39]. Its rather rapid metabolism and clearance means that apomorphine has a $t_{1 / 2}$ of around 33 min [35, 38]. Overall, inter-individual variability in $t_{\max }, C_{\max }$, and area under the plasma concentration-time curve (AUC) is high $[35,38,40]$ because of a variety of factors, including regional fat, blood flow and differences in metabolic enzymatic profiles. On the other hand, intra-individual variability is low. In clinical practice, this translates into a need for individual titration when starting apomorphine therapy. After a single dose in patients with $\mathrm{PD}$, the onset of a clinical response usually occurs within 7-10 min after the subcutaneous injection and lasts for about 45-60 min [40], making intermittent subcutaneous injections of apomorphine a highly suitable rescue therapy for patients experiencing "on/off" fluctuations during chronic levodopa therapy.

\section{Efficacy}

Since the pioneering studies in the 1980s [28], multiple open-label series have confirmed the efficacy of apomorphine in reversing severe, sudden "off" states in advanced PD despite optimized oral therapy [28, 33, 41-45]. In most cases, the primary outcome was the reduction of time spent in "off" obtained with continuous subcutaneous apomorphine infusion (CSAI) or intermittent subcutaneous pen injections. Reduction of dyskinesia severity with chronic subcutaneous infusions was also reported but was inconsistent between studies [18, 46-48]. Studies comparing the efficacy of apomorphine and levodopa have repeatedly shown the two drugs to have equivalent effect sizes [3, 49]. Only a few studies assessing intermittent subcutaneous injection or continuous infusions of apomorphine were placebo controlled, but these have confirmed results from a large body of evidence from open-label use [45, 50].

\subsection{Efficacy of Apomorphine Compared with Levodopa}

Apomorphine and levodopa show an almost overlapping efficacy when treating PD motor symptoms.

In one crossover open-label study, no difference was observed between apomorphine and levodopa in all outcome variables, including hand tapping scores, walking time, severity of tremor, dyskinesia score and a modified Webster disability scale to evaluate disability due to PD. The mean duration of the motor effect was 56 min (range 30-80) for apomorphine and $211 \mathrm{~min}$ (range 145-315) for oral levodopa. Time to onset was 3-14 min for apomorphine (mean 7.9) and 19-75 min for levodopa (mean 35.4) [3]. This 
comparative study proved for the first time that apomorphine has virtually indistinguishable efficacy on motor symptoms compared with levodopa but a considerably shorter duration of effect. These results were later confirmed in a doubleblind single-dose study using apomorphine or levodopa [49].

\subsection{Efficacy of Intermittent Apomorphine Injections}

Chronic treatment of PD with levodopa is compromised by the development of motor fluctuations despite optimized oral dopaminergic therapy [51]. This lack of a stable response to therapy has a significant negative impact on quality of life because of the many motor and non-motor disabilities associated with the "off" state and reduced autonomy in planning activities because of the unpredictability of "off" phases. A large observational study in 1000 patients with PD experiencing "off" episodes despite best medical management showed that they had to live with an average of $2-3 \mathrm{~h}$ of "off" time per day [52].

Numerous studies have assessed the efficacy of apomorphine injections in patients with PD with fluctuations [18, 28, 42, 46, 50, 53] (Tables 1 and 2). These studies consistently reported a marked reduction in the number of daily "off" periods and other "off"-related phenomena such as early morning dystonia, urinary disfunction and pain.

Three pivotal randomized, placebo-controlled trials were conducted in the USA between 2001 and 2007, leading to the approval of the drug in an injection pen for the acute intermittent treatment of "off" episodes in advanced PD [33, 54-56].

The first of these US registration studies (APO202) was a randomized, double-blind, placebo-controlled, parallelgroup trial assessing the safety and efficacy of subcutaneous injections of apomorphine hydrochloride for "off" state periods in apomorphine-naive patients with PD with motor fluctuations despite aggressive oral therapy. The study was divided into two phases. Phase one consisted of an inpatient uptitration of the apomorphine dose to reverse a practically defined "off" period. Phase two involved a 1-month period of outpatient observation of drug effectiveness for reversal of "off"-state events. A 2-week observation period before the inpatient phase allowed the average "off" hours for each patient to be established at baseline. On the first day of the inpatient phase, all subjects underwent an unblinded levodopa challenge with their normal morning levodopa dose to establish their clinical response to dopaminergic therapy. On the second day, patients started in an "off" state and the Unified Parkinson's Disease Rating Scale (UPDRS) motor response was evaluated with increasing doses of apomorphine or placebo. Apomorphine was started at $2 \mathrm{mg}$ and increased in 2-mg steps to a 10-mg maximum; the dose was uptitrated until patients reached a reduction of the UPDRS motor score of at least $90 \%$ of that recorded with the levodopa challenge. The primary efficacy indicator was the change UPDRS part III from predose to postdose. Apomorphine showed a reduction of 23.9 points (62\% improvement)

Table 1 Summary of open-label studies assessing the efficacy of intermittent subcutaneous injections of apomorphine in patients with Parkinson's disease

\begin{tabular}{|c|c|c|c|c|c|c|c|c|c|}
\hline Study & Pts $(N)$ & $\begin{array}{l}\text { Study dura- } \\
\text { tion, months }\end{array}$ & $\begin{array}{l}\text { Mean injec- } \\
\text { tion dose/ } \\
\text { mean total } \\
\text { daily dose, } \\
\text { mg }\end{array}$ & $\begin{array}{l}\text { Minutes } \\
\text { to clinical } \\
\text { onset }\end{array}$ & $\begin{array}{l}\text { Duration } \\
\text { of effect, } \\
\text { minutes }\end{array}$ & $\begin{array}{l}\text { Average daily } \\
\text { "off" reduc- } \\
\text { tion, hours }\end{array}$ & $\begin{array}{l}\text { Average daily } \\
\text { "off" reduc- } \\
\text { tion, } \%\end{array}$ & $\begin{array}{l}\text { Levodopa } \\
\text { reduction, } \\
\mathrm{mg}\end{array}$ & $\begin{array}{l}\text { Levodopa } \\
\text { reduction, } \\
\%\end{array}$ \\
\hline $\begin{array}{l}\text { Poewe et al. } \\
\text { [102] }\end{array}$ & 12 & 6.5 & $4.0 / 9.6$ & $5-15$ & $60-150$ & 2.7 & 56 & NR & NR \\
\hline $\begin{array}{l}\text { Poewe et al. } \\
\text { [103] }\end{array}$ & 17 & 7.2 & $3.8 / 12.2$ & NR & NR & 3.0 & 64 & -77 & -8 \\
\hline $\begin{array}{l}\text { Frankel et al. } \\
\text { [46] }\end{array}$ & 30 & 13.5 & $2.2 / 10.2$ & 7.5 & $60(20-120)$ & 4 & 58 & -39 & -5 \\
\hline $\begin{array}{l}\text { Kempster } \\
\text { et al. [3] }\end{array}$ & 14 & Single dose & $2 / 2$ & 7.9 & $56(30-80)$ & NR & NR & NR & NR \\
\hline $\begin{array}{l}\text { Hughes et al. } \\
\text { [17] }\end{array}$ & 15 & 6 doses & $3.4 / \mathrm{NR}$ & $5-25$ & $10-107$ & NR & NR & NR & NR \\
\hline $\begin{array}{l}\text { Hughes et al. } \\
\text { [104] }\end{array}$ & 49 & 27 & $2-5 / 11.7$ & NR & NR & 3.6 & 50 & -61 & -7 \\
\hline $\begin{array}{l}\text { Esteban } \\
\text { Muñoz et al. } \\
{[105]}\end{array}$ & 11 & 23 & $3 / 9$ & 9.5 & 60.9 & 2.8 & 45 & +109 & +15 \\
\hline $\begin{array}{l}\text { Pietz et al. } \\
\text { [47] }\end{array}$ & 24 & 22 & $1.9 / 9.7$ & 10 & $47.5(25-90)$ & NR & 20.5 & +225 & +27 \\
\hline
\end{tabular}

$N R$ not reported, $P D$ Parkinson's disease, pts patients 


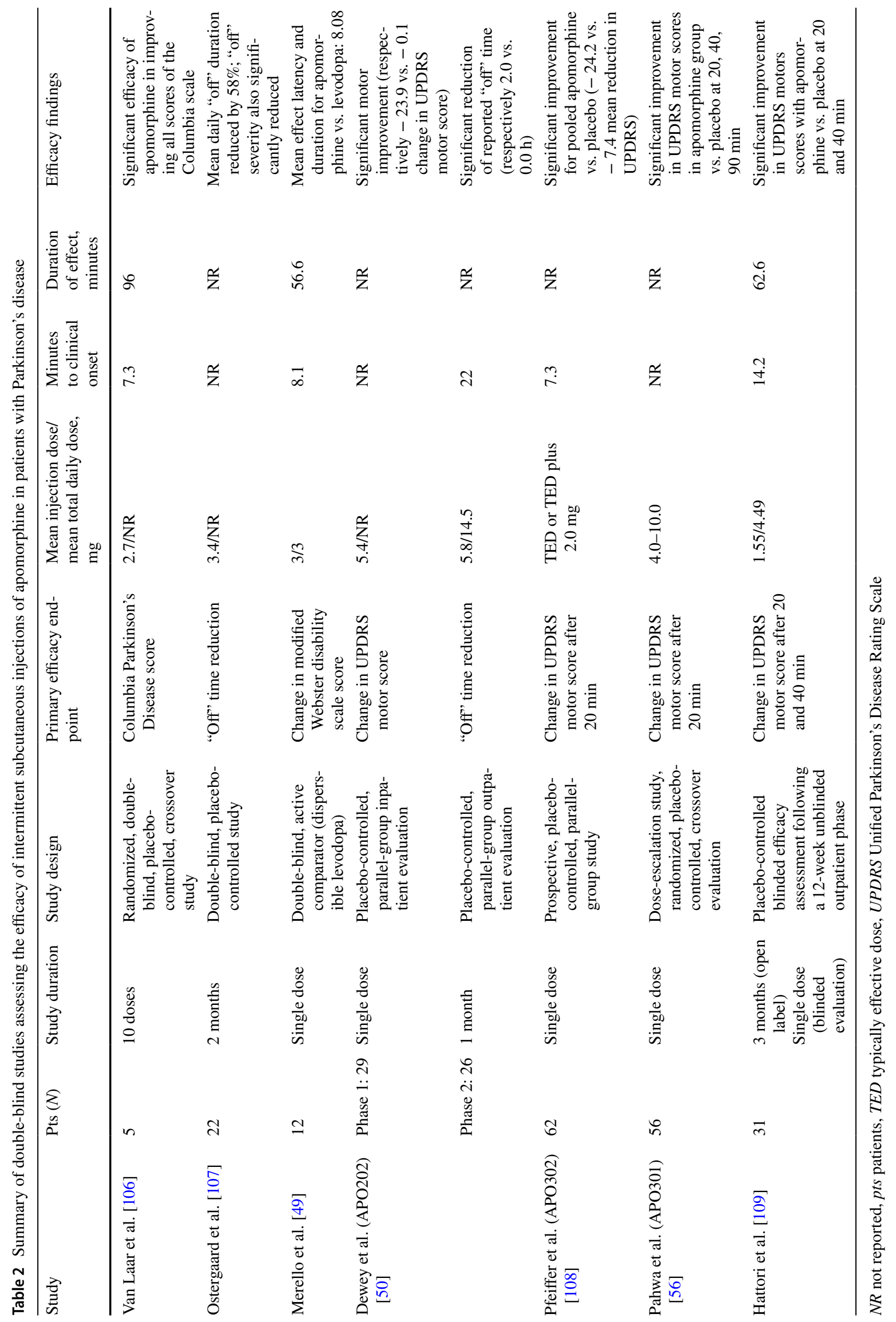


compared with placebo. Apomorphine's inter-individual variability in both pharmacokinetic parameters and efficacy was addressed in this study, with an individual titration reaching an optimal dose. The average inpatient apomorphine dose needed to reach a satisfying "on" $(5.4 \mathrm{mg})$ closely matched the average dose used in the outpatient phase $(5.8 \mathrm{mg})$. No placebo effect was described, and almost all subjects reached the maximum placebo dose in uptitration. During the outpatient phase of the study, apomorphine was decidedly more effective in aborting "off" episodes (95\%) than was placebo (23\%), measured via patient home diaries. Apomorphine showed an average reduction in "off" time of $2.0 \mathrm{~h}$ per day compared with baseline. This was the first study to assess the efficacy of intermittent treatment with apomorphine in reducing "off" time, in both inpatients and outpatients and compared with placebo. Moreover, the predictive nature of inpatient test responses on outpatient therapeutic response was established.

APO301 was a crossover trial enrolling apomorphineexperienced patients: participants received their usual apomorphine dose or a placebo, followed by the other treatment on the next day. Using the motor score of the UPDRS as a primary outcome measure, the study showed the superiority of apomorphine versus placebo at 10, 20 and 60 min postadministration. APO302 was a placebo-controlled, singlevisit study to assess the efficacy of apomorphine in patients already receiving apomorphine and who were experiencing "off" periods during the day despite their oral dopaminergic therapy. A subgroup of patients received their usually effective apomorphine dose and an additional $2 \mathrm{mg}$ to evaluate the tolerability of excess drug during administration and to determine whether patients with motor fluctuations receiving chronic apomorphine therapy would benefit from a higher apomorphine dose. The study showed that apomorphine brings fast relief from "off" periods even after long-term treatment. Moreover, once the optimal dose is defined for a patient, no significant advantage (measured as improvement in UPDRS part III) is gained by increasing that dose. Indeed, the only consequence of raising the apomorphine dose in the study was an increased rate of adverse events. These results mirror the common clinical experience that the optimal dose of apomorphine to relieve "off" time in individuals rarely needs to be changed.

APO303 [57] was an open-label dose-escalation study with a placebo-controlled crossover evaluation to further explore the safety and efficacy of apomorphine in patients with advanced PD naïve to apomorphine treatment. The study results again confirmed apomorphine's efficacy in "off" periods assessed as UPDRS motor improvement at 20, 40 and 90 min post-injection compared with placebo. Both efficacy and adverse events were dose related. At doses $>6 \mathrm{mg}$, motor improvements were not significant, but the incidence of adverse events kept increasing. This finding suggests no further benefit from increasing the dose of apomorphine in patients who are already receiving their optimal therapeutic dosage. Intermittent apomorphine maintained its effectiveness in improving mobility after 6 months of openlabel treatment. APO303 was conducted as a substudy of the larger open-label trial assessing the safety profile of continued use of intermittent subcutaneous apomorphine to treat "off" episodes in patients with advanced PD [57].

Additional evidence on the efficacy of the drug came from a recent phase IV multicenter study (AM IMPAKT) assessing the effect of apomorphine injections in patients with prolonged morning akinesia despite their levodopa morning dose [42]. A dose failure was defined as the inability to reach an "on" phase in $60 \mathrm{~min}$ after levodopa intake. Patients completed a 7-day levodopa baseline period by recording their time to "on" after each morning levodopa dose. Patients who experienced dose failures were then titrated to an optimal dose of apomorphine (2-6 mg) and started a 7-day treatment period with morning apomorphine injections instead of their normal morning levodopa dose. To prevent nausea and vomiting, subjects were started on antiemetic therapy with trimethobenzamide. The reduction in time to "on" (mean reduction $37.14 \mathrm{~min}$ ) and the rate of dose failure ( $46 \%$ with levodopa vs. $7 \%$ with apomorphine) provided further evidence in favor of intermittent apomorphine injections. The study showed that subcutaneous apomorphine injections provided a rapid and reliable "on" state for patients experiencing morning akinesia, possibly resulting from bypassing problems associated with gastrointestinal delivery and levodopa absorption.

\subsection{Efficacy of Continuous Subcutaneous Apomorphine Infusion (CSAI)}

CSAI, together with deep-brain stimulation (DBS) and intestinal gel infusions of levodopa/carbidopa (LCIG) is one of the therapeutic cornerstones for advanced PD [58, 59]. Unlike oral therapies, infusion therapies are based on constant drug delivery, aiming for continuous dopaminergic stimulation. Continuous striatal dopamine receptor stimulation not only reduces response oscillations but also has the potential to prevent or reduce drug-induced dyskinesias.

Unlike intermittent apomorphine injections, until recently there has been a striking lack of randomized placebocontrolled studies assessing the efficacy of CSAI. Several uncontrolled open-label studies consistently reported the efficacy of CSAI as monotherapy or in addition to levodopa [47, 60-63], with an average "off" time reduction of 59.3\% and a reduction of dyskinesia severity of $32.4 \%$ [64]. In line with these results, a prospective study confirmed a marked reduction in the frequency and severity of dyskinesias in patients with PD treated with CSAI [65]. Table 3 summarizes the results of the different studies. 
Table 3 Summary of open-label studies assessing the efficacy of subcutaneous apomorphine infusion in patients with Parkinson's disease

\begin{tabular}{lllllll}
\hline Study & Pts $(N)$ & $\begin{array}{l}\text { Study dura- } \\
\text { tion, months }\end{array}$ & $\begin{array}{l}\text { Infusion duration, h/day } \\
\text { Apomorphine } \\
\text { total DD, mg }\end{array}$ & $\begin{array}{l}\text { Daily time } \\
\text { in "off” } \\
\text { decrease, } \%\end{array}$ & Daily levodopa decrease, \% \\
\hline Frankel et al. [46] & 25 & 22 & $\mathrm{NR}$ & 89 & 45 & 22 \\
Hughes et al. [104] & 22 & 36 & 16.9 (at 12 months) & 80.8 & 40 & 14 (at 12 months) \\
Pietz et al. [47] & 25 & 44 & 24 & 112.5 & 50 & 50 \\
Stocchi et al. [112] & 30 & 60 & 12 & 51.6 & $\mathrm{NR}$ & 47 \\
Manson et al. [67] & 64 & 34 & $12-24$ & 98 & 49 & 63.5 \\
Tyne et al. [113] & 80 & 25 & 13.5 & 69.8 & $\mathrm{NR}$ & 24 (after 2 months) \\
García Ruiz et al. [62] & 82 & 20 & 14 & 72 & 79.5 & 80 \\
Drapier et al. [114] & 23 & 12 & 15.1 & 62.6 & 36 & 26 \\
Kimber et al. [115] & 36 & 21.5 & $\mathrm{NR}$ & $\mathrm{NR}$ & $\mathrm{NR}$ & 22.7 (LEDD decrease) \\
Rambour et al. [116] & 81 & 28 & $\mathrm{NR}$ & 105.9 & $\mathrm{NR}$ & 37.8 \\
Martinez-Martin et al. [70] & 43 & 6 & 15.9 & 58.5 & $\mathrm{NR}$ & 30 \\
Drapier et al. [117] & 142 & 6 & 12.7 & 66 & $\mathrm{NR}$ & 24 \\
Borgemeester et al. [63] & 125 & 32.3 & 16.6 & 78 & 77.7 & 32 \\
Sesar et al. [118] & 230 & 26.3 & 16.3 & & 20.4 \\
\hline
\end{tabular}

$D D$ daily dose, $N R$ not reported, $L E D D$ levodopa equivalent daily dose, pts patients

High-level evidence for the efficacy and safety of CSAI was recently provided by the TOLEDO trial, the first-ever randomized, placebo-controlled, double-blind, multicenter trial to assess apomorphine subcutaneous infusion in patients with PD [45]. Patients with PD with a disease diagnosis for more than 3 years and with motor fluctuations not controlled by optimal medical therapy received either $3-8 \mathrm{mg} / \mathrm{h}$ apomorphine or placebo infusion during waking hours (16 h/day) for 12 weeks. During the first 4 weeks, the flow rate of the study drug and the other oral therapies could be adjusted, and the following 8 weeks were a maintenance period. Apomorphine significantly reduced more "off" time than did placebo ( -2.47 vs. $-0.58 \mathrm{~h} /$ day). Additionally, the dose and number of oral antiparkinsonian medications was reduced in patients receiving CSAI. It was suggested that CSAI can reduce "off" time without increasing troublesome parallel dyskinesia. These results confirm that CSAI has efficacy comparable to that of LCIG infusion in treating motor fluctuations in advanced PD [66].

Dyskinesia reduction appears to be most pronounced in patients able to rely on CSAI as a monotherapy, since improvements in dyskinesia usually correlate with the concomitant decrease of oral medication [65, 67].

\subsection{Apomorphine and Non-Motor Symptoms}

While the efficacy of apomorphine in treating motor symptoms of PD has been the main focus of this review, the drug may also have an effect on non-motor aspects of the disease. NMS are experienced by $>90 \%$ of patients with PD during the course of the disease and are also important factors influencing health-related quality of life. The NMS spectrum is quite broad and includes neuropsychiatric symptoms, sleep impairment, pain, cognitive impairment, dementia and depression. Patients with PD experience an average of $8.3 \mathrm{NMS}$ during the course of the disease, with only $<2.5 \%$ patients being completely NMS free [68].

An observational open-label study investigated the effects on NMS of CSAI compared with conventional treatment (oral and patch therapy) and reported positive effects on the Non-Motor Symptom Scale (NMSS) after 1 year of follow-up [69]. Specifically, sleep, mood, gastrointestinal (including constipation) and perceptual problems and urinary domains improved. Similar results came from the Euroinf study, which assessed the effects of CSAI and LCIG on NMS and showed that both infusion-based therapies were effective in improving motor symptoms, NMS and quality of life scores [70].

Several authors have focused on the effect of apomorphine on neuropsychiatric symptoms, stating that apomorphine seems to be well-tolerated in patients with paranoid ideas and visual hallucinations [71, 72]. One study reported reductions in hallucinations in 12 non-demented patients receiving CSAI concurrent to a reduction in their oral antiparkinsonian medications, but this observation could not differentiate between effects of reductions in oral medications versus the true "antipsychotic" effects of apomorphine [73]. In a 5-year prospective comparative study between DBS and CSAI, a worsening of the Neuropsychiatric Inventory Questionnaire was observed in the DBS group but not in the apomorphine group. 
It has been suggested that the hypothesized antipsychotic effects of apomorphine could be related to its structural piperidine moiety, which is also part of several antipsychotic molecules. Along these lines, apomorphine has been claimed to have a positive effect on visual hallucinations and to not exacerbate symptoms in patients with pre-existing visual hallucinations, possibly related to apomorphine's capacity to act as a 5HT2A receptor antagonist [71].

Additionally, when compared with other dopamine agonists, apomorphine therapy seems to be associated with a lower incidence of emergent impulse control disorders (ICDs) $[74,75]$. Since activation of $\mathrm{D}_{3}$ receptors by oral dopamine agonists has been related to the emergence of ICDs in PD [76], the lower $\mathrm{D}_{3}: \mathrm{D}_{2}$ ratio of apomorphine compared with pramipexole or ropinirole could be a potential explanation for a lowered risk to induce ICDs, although precise data on the incidence of ICDs in patients treated with apomorphine compared with those receiving other dopamine agonists are lacking.

A recent experimental study showed that apomorphine injections reduced intraneural amyloid $\beta$ protein and improved short-term memory in a murine Alzheimer's disease model [77]. Based on these findings, a recent retrospective clinicopathological study investigated non-demented subjects with PD who used apomorphine antemortem compared with matched controls. The study showed significantly reduced amyloid $\beta$ protein among apomorphine-treated subjects using amyloid positron-emission tomography imaging, giving rise to speculations that the drug may represent a potential therapy to reduce cognitive impairment in PD [78].

In summary, data on the efficacy of apomorphine in NMS remains very limited but point to a possible benefit in sleep dysfunction, neuropsychiatric symptoms, urinary dysfunction, mood and gastrointestinal symptoms as a corollary to "off" time reduction in patients with fluctuating PD. More studies using non-motor assessments as outcome variables are warranted to improve our understanding of the different NMS subtypes in which apomorphine could be beneficial.

\section{Safety}

Apomorphine is usually well-tolerated, and adverse events range from mild to moderate in intensity. Overall, the incidence of adverse events seems to be generally higher in patients receiving CSAI than in those treated with intermittent injections [79].

Cutaneous and subcutaneous adverse reactions-including bruising, subcutaneous nodules and, rarely, necrosis or abscess formation at injection or infusion sites-are the most common, followed by nausea and somnolence. Histologically, subcutaneous nodules present as infiltrates containing eosinophils, lymphocytes and histiocytes as well as melanin-like pigments and, in chronic conditions, fibrosis [80, 81]. Although these cutaneous reactions are usually mild, they can, in rare cases, lead to drug discontinuation because of abscess and necrosis. This risk can be reduced by ensuring thorough skin hygiene, using new needles for each injection, changing the site of injection and using localized massage and ultrasound therapy [82].

Nausea and vomiting in response to apomorphine can be controlled with preventive temporary administration of antiemetics (such as domperidone or trimethobenzamide) [27]. Nausea, vomiting and hypotension mainly occur at initiation of apomorphine, where they seem to be more common in patients treated with intermittent subcutaneous apomorphine than with CSAI [47].

Sedative effects are also common with apomorphine, whereas other central dopaminergic side effects such as confusion, hallucinations and psychosis are less commonly observed than with oral dopamine agonists. The latter may be related to differences in the dopamine receptor subtype affinity of apomorphine [72]. Data on the relationship between apomorphine and ICDs are limited. Binge eating, compulsive sexual disorder and punding have been reported, but the incidence of ICDs seems to be low, with only rare cases requiring discontinuation of CSAI [72, 83, 84].

Hematologic adverse events are a rare complication of apomorphine therapy, but the risk of developing autoimmune hemolytic anemia in patients undergoing CSAI should be appropriately monitored with regular blood cell counts, checks of hemolytic parameters and Coombs test to detect antibodies targeting red blood cells. How frequently these tests should be performed during chronic treatment with apomorphine is somewhat controversial. The mechanism responsible for this autoimmune response remains unclear [85].

Apomorphine has been reported to induce QT interval prolongation in post-marketing surveillance [110]; however, no evidence yet shows a direct link between drug administration, QT prolongation and cardiac arrest. Conversely, apomorphine may have a broader cardiovascular safety margin than originally thought [111].

Safety results from controlled trials of intermittent subcutaneous apomorphine injections reveal a generally mildto-moderate adverse event profile. In the APO202 study, adverse event rates were almost identical between the placebo and the apomorphine group (89 vs. $85 \%$ ), and events were almost all classified as treatment-emergent adverse events (TEAEs). Events only reported in the apomorphine group were yawning (40\%) and somnolence (35\%) [54]. Dyskinesias as an adverse event were reported in $35 \%$ of the apomorphine-treated subjects versus $11 \%$ of the placebo group. During the inpatient phase of this trial, nausea was reported in $30 \%$ of subjects receiving apomorphine, whereas this was almost never the case in the subsequent outpatient 
phase. All study participants received trimethobenzamide as antiemetic prophylaxis.

APO401 was a large open-label study $(n=546)$ assessing the long-term safety of intermittent subcutaneous apomorphine [33]. During the 12-month treatment period, 93\% of all patients with PD in the study experienced at least one adverse event. Most of these events were regarded as mild or moderate in severity. The most common TEAEs were nausea and vomiting (33\%), falls (33\%), dyskinesias (24\%), dizziness (22\%), somnolence (21\%), hallucinations (19\%), yawning (16\%) and injection site bruising (15\%). A total of 187 patients discontinued treatment because of adverse events. Serious adverse events were reported in 199 (36.4\%) patients, but most were considered only remotely related or definitely unrelated to apomorphine. In total, 19 patients experienced 27 serious adverse events that were possibly or probably related to apomorphine. Among these 27, the most common were syncope $(n=3)$, drug-induced psychosis $(n=3)$, postural hypotension $(n=2)$ and falls $(n=2)$. Safety assessment from the only placebo-controlled trial with CSAI (TOLEDO) reported adverse events in line with the evidence presented by previous observational studies [45]. Apomorphine infusion was well-tolerated, and no unexpected safety signals were observed in this trial, with most of the adverse events being of mild or moderate intensity. Overall, 93\% (50/54) of patients in the apomorphine group had at least one TEAE compared with 57\% (30/53) of patients in the placebo group. The most common TEAEs were skin reactions (44 vs. $0 \%$ ), nausea (22 vs. $9 \%$ ) and somnolence (22 vs. $4 \%$ ). Not surprisingly, neuropsychiatric TEAEs occurred more commonly in the apomorphine group (mild hypersexuality, $n=1$; mild punding, $n=2$; mild to severe confusion episodes, $n=1$; moderate psychosis, $n=1$; and mild to moderate hallucinations, $n=2$ ) than in the placebo group (episodes of mild confusion, $n=2$; mild hallucinations, $n=2$ ). With dose reduction, almost all neuropsychiatric TEAEs were resolved. Six patients (11\%) in the apomorphine and none of the placebo group withdrew from the study because of treatment-related adverse events. Half of the patients withdrew because of serious adverse events (severe orthostatic hypotension, $n=1$; myocardial infarction, $n=1$; abnormal persistent non-hemolytic hematology test results). The other patients withdrew because they experienced visual hallucinations $(n=1)$, moderate gait disturbance $(n=1)$ or mild infusion-site erythema $(n=1)$. All events leading to study withdrawal, except for myocardial infarction, were thought to be treatment related. Indeed, all were resolved after cessation of apomorphine.

Some possible drug-drug interactions should be considered with apomorphine treatment. These include the concomitant administration of apomorphine with $5 \mathrm{HT}_{3}$ antagonists such as ondansetron, which may induce severe hypotension and syncope, and combination with drugs associated with QT/QTc interval prolongation, especially when domperidone is given for antiemetic prophylaxis. Indeed, domperidone may cause QT/QTc prolongation and is associated with increased risk of ventricular tachyarrhythmia and sudden cardiac death in patients with PD with preexisting cardiac disease [86]. Given the potential for cardiac side effects with domperidone, its use has been restricted by the European Medicines Agency [87].

Apomorphine should be used carefully in patients with orthostatic hypertension because its ability to lower systolic and diastolic blood pressure may aggravate symptoms.

When initiating apomorphine therapy, antiemetic prophylaxis and close medical supervision are recommended to maximize adherence.

\section{Apomorphine in Parkinson's Disease: Practical Considerations}

Intermittent injections are a viable rescue medication for patients who are already optimized on oral medications and are still experience troubling "off" periods. Apomorphine injections can also be beneficial in patients with impaired gastric emptying that results in delayed levodopa absorption. Suitable candidates for intermittent apomorphine injections should be capable of injecting themselves or have a caregiver able to inject them when needed [88]. Exhaustive injection training (or pump training for patients starting continuous infusion) for patients and caregivers with a physician or a nurse experienced in the treatment of advanced PD plays a fundamental role in therapy compliance and in preventing adverse events. The injections are given via a multidose pen loaded with a solution of apomorphine hydrochloride 10 or $20 \mathrm{mg} / \mathrm{mL}$. When beginning intermittent apomorphine injection therapy, the patient is asked to come to the clinic without taking their usual dopaminergic medications for dose titration; once the patient reaches an "off" episode in clinic, a first dose of apomorphine $2 \mathrm{mg}$ should be administered. Time to onset of effect, duration of effect and adverse effects must be recorded during a monitoring period of $1 \mathrm{~h}$ from injection. Until the desired motor response is obtained, the dose can be increased by $1-1.5 \mathrm{mg}$; the optimal dose for most patients usually ranges from 2 to $6 \mathrm{mg}$ and, once it is achieved, further dose adjustments over time are not usually required. The daily number of injections varies considerably between patients, but subjects who require more than five or six injections per day are usually recommended to switch to CSAI [88].

CSAI is administered via a portable pump system that delivers a continuous dose, with the possibility of releasing a rescue bolus if needed. The duration of infusion is normally 12-16 h (waking time), but a $24-\mathrm{h}$ regimen can also be programmed for patients experiencing nocturnal hypokinesia 
[89]. Patients with PD who have "off" periods no longer controlled with optimized oral therapy or who need apomorphine rescue doses too frequently are suitable candidates for CSAI. The pump can also be an alternative to surgical therapy or to enteral levodopa infusion [90]. For patients starting CSAI in the inpatient setting, domperidone $10 \mathrm{mg}$ (or trimethobenzamide in countries where domperidone is not available) three times daily from 1 day before initiation to 3-7 days in total is strongly recommended to prevent nausea [90]. On the first day, apomorphine treatment is started at a dose of 0.5 or $1 \mathrm{mg} / \mathrm{h}$. Uptitration is usually with 0.5 or $1 \mathrm{mg} / \mathrm{h}$ daily increments, and the optimal infusion rate ranges from 4 to $7 \mathrm{mg} / \mathrm{h}$ for most patients. Concomitantly, oral dopamine agonists and other antiparkinsonian drugs are gradually discontinued. During the titration phase, levodopa is also usually reduced, and discontinued if possible in patients with dyskinesia [90]. The same uptitration protocol should be used for outpatients but with a slower increase in infusion rates.

\section{Alternative Apomorphine Delivery Strategies}

To date, the main administration route for apomorphine in PD has been subcutaneous, either as a continuous infusion or as an intermittent pen injection. This route has proven effective, but skin reactions are among the most common adverse events and can complicate treatment or lead to withdrawal. For some patients, this delivery may also be problematic because of needle phobia; for others, the pen injection may prove challenging for resolving an acute "off" phase because of bradykinesia and tremor. Despite its remarkable efficacy, apomorphine suffers from the lack of an "easier" and less invasive delivery system. Several alternative delivery routes have therefore been tested, and some are in active clinical development.

Pulmonary delivery of drugs has the potential of very rapid entry into the systemic circulation through the lung's extensive alveolar surface with no hepatic first-pass effect, making it an attractive strategy to achieve rapid onset of effect to "rescue" patients from "off" periods. An apomorphine powder formulation for delivery via an inhaler device (VR040) has been developed and used in a single-center, placebo-controlled, randomized study in patients with motor fluctuations. Inhaled apomorphine proved to be well-tolerated, but efficacy was limited [91]. Two larger studies followed, in which the drug proved to have rapid absorption (2-7 min) mirrored by a rapid clinical reversal from the "off" state (10 min) [92, 93]. These short-term studies reported no pulmonary safety concerns, but no reports of further clinical development of this agent have been released.
Oral apomorphine is considered infeasible because of the almost complete first-pass hepatic metabolism of the molecule [35]. However, the administration of apomorphine and its prodrug (dipalmitoyl apomorphine) via oral lipid-based formulations has recently been reported in animal models of PD. This formulation is still in the preclinical phase but may have the potential to achieve steady dopaminergic stimulation because of its sustained drug release [94].

Sublingual formulations of apomorphine have been recognized as a viable alternative to the subcutaneous route for decades [95-97]. A sublingual formulation needs no needles, causes no pain and is easily administered, even during a severe "off" phase. A novel sublingual apomorphine formulation consisting of a two-film strip that contains apomorphine in a bilayer (APL-130277) has been shown to reliably revert "off" periods in several clinical trials. A proof-ofconcept study for this new formulation was conducted with patients with PD coming to the clinic in an "off" state and receiving APL-130722 (10-30 mg). Of the 19 patients, 15 achieved a full "on" response in $<30 \mathrm{~min}$, with the response lasting $50 \mathrm{~min}$ on average [98]. A phase III double-blind placebo-controlled trial enrolling 109 patients showed significantly greater improvements in UPDRS motor scores $30 \mathrm{~min}$ post-dosing with APL-130722 (primary endpoint) and a significantly greater proportion of patients achieving a full "on" state after 30 min (key secondary endpoint). Nausea, daytime somnolence and oral cavity-related adverse events (mucosal erythema, glossodynia, dry mouth, lip edema, throat irritation) were more common with active drug than with placebo [99]. A phase III open-label, randomized, crossover trial with blinded rating to evaluate APL-130277 compared with subcutaneous apomorphine in patients with PD with motor fluctuation is currently underway (ClinicalTrials.gov identifier: NCT03391882).

Finally, despite the already discussed drawbacks of subcutaneous delivery, room to improve pump technology for more user-friendly modes of the traditional apomorphine delivery route exist. Patch pumps of small size and weight are in routine clinical use in different fields, including insulin delivery in diabetes. They have in-built technology to program delivery rates and external control of needle insertion and delivery, with minimal inconvenience to patients. Their use for CSAI requires novel apomorphine formulations with enhanced solubility, enabling smaller volumes to meet daily dose requirements. Experiments conducted in minipigs with a novel apomorphine formulation (ND0701) have shown better local safety profiles and tolerability than regular apomorphine hydrochloride [100]. Potentially, this would allow for safer, more comfortable and easier delivery in advanced PD. First results coming from a phase I clinical study suggest that ND0701 may have better tolerability and safety than and similar bioavailability to the injectable formulations available on the market [101]. 


\section{Conclusions}

Apomorphine has a long and interesting history as the oldest dopamine agonist used in PD. Despite being initially received with skepticism, it has proved to have efficacy comparable to that of levodopa, the gold standard therapy for all stages of PD. Thanks to the cumulative evidence provided by several studies, apomorphine should be considered as a monotherapy or an effective adjunctive treatment for patients with advanced PD and levodopa-related motor complications. Its lipophilic molecule allows for rapid and effective treatment of "off" episodes. Its low bioavailability has limited its administration to subcutaneous intermittent injections or continuous subcutaneous infusion. Intermittent injections of subcutaneous apomorphine in addition to the oral therapy provide great relief in patients with unpredictable "off" phases, and temporary coadministration with an antiemetic drug has significantly increased tolerability. Delivered as a continuous infusion, apomorphine leads to a remarkable decrease of time spent in "off" with no concurrent increase in dyskinesia. While this delivery method is effective, research is moving toward new strategies and new formulations of the drug to decrease complications and increase the handiness and safety and efficacy profiles. New studies are also warranted to explore the possible efficacy of apomorphine earlier in the course of the disease [58].

\section{Compliance with Ethical Standards}

Funding No sources of funding were used to conduct this study or prepare this manuscript. Open access funding provided by University of Innsbruck and Medical University of Innsbruck.

Conflicts of interest Federico Carbone has no conflicts of interest that are directly relevant to the content of this review. Atbin Djamshidian has received consulting fees from Abbvie and Grünenthal. Klaus Seppi has received fees from Teva, UCB, Lundbeck, AOP Orphan Pharmaceutical AG, Roche, Grünenthal and Abbvie; honoraria and research grants from the International Parkinson and Movement Disorder Society; and research grants from the FWF Austrian Science Fund and Micheal J. Fox Foundation outside of the submitted work. Werner Poewe has received consulting fees from Britannia Pharmaceuticals for planning and implementation of the TOLEDO study; consulting fees from Grünenthal in relation to apomorphine educational activities; and lecture fees from Britannia Pharmaceuticals and Grünenthal related to symposia on the TOLEDO study and for apomorphine educational activities.

Open Access This article is distributed under the terms of the Creative Commons Attribution-NonCommercial 4.0 International License (http://creativecommons.org/licenses/by-nc/4.0/), which permits any noncommercial use, distribution, and reproduction in any medium, provided you give appropriate credit to the original author(s) and the source, provide a link to the Creative Commons license, and indicate if changes were made.

\section{References}

1. Tysnes OB, Storstein A. Epidemiology of Parkinson's disease. J Neural Transm. 2017;124(8):901-5.

2. Poewe W, Seppi K, Tanner CM, Halliday GM, Brundin P, Volkmann J, et al. Parkinson disease. Nat Rev Dis Prim. 2017;3:17013.

3. Kempster PA, Frankel JP, Stern GM, Lees AJ. Comparison of motor response to apomorphine and levodopa in Parkinson's disease. J Neurol Neurosurg Psychiatry. 1990;53(11):1004-7.

4. Poewe WH, Lees AJ, Stern GM. Low-dose L-dopa therapy in Parkinson's disease: a 6-year follow-up study. Neurology. 1986;36(11):1528-30.

5. Sweet RD, McDowell FH. Five years' treatment of Parkinson's disease with levodopa. Therapeutic results and survival of 100 patients. Ann Intern Med. 1975;83(4):456-63.

6. Emboden WA. Transcultural use of narcotic water lilies in ancient egyptian and maya drug ritual. J Ethnopharmacol. 1981;3(1):39-83.

7. Emboden WA. The mushroom and the water lily: literary and pictorial evidence for Nymphaea as a ritual psychotogen in mesoamerica. J Ethnopharmacol. 1982;5(2):139-48.

8. Bertol E, Fineschi V, Karch SB, Mari F, Riezzo I. Nymphaea cults in ancient Egypt and the New World: a lesson in empirical pharmacology. J R Soc Med. 2004;97(2):84-5.

9. Matthiessen A, Wright CRA. Researches into the Chemical constitution of the opium bases. Part I. on the action of hydrochloric acid on morphia. Proc R Soc Lond. 1868;17:455-60 (6 pages).

10. Arppe AE. Ueber eine merkwürdige Veränderung des Morphins durch Schwefelsäure. Ann der Chemie und Pharm. 1845;55(1):96-101.

11. Taba P, Lees A, Stern G. Erich Harnack (1852-1915) and a short history of apomorphine. Eur Neurol. 2013;69(6):321-4.

12. Pierce FM. Notes on Apomorphia. BMJ. 1870;1(478):204.

13. Hare F. On alcoholism its clinical aspects and treatment. London: J\&A Churchill; 1912.

14. Gee S. On the action of a new organic base, apomorphia. Clin Soc Trans. 1869;2:166-9.

15. Siebert V: Untersuchungen über die physiologischen Wirkungen des Apomorphin. Inaugural-Dissertation zur Erlangung der Doctorgrades. Dorpat, Druck von Heinrich Laakmann, 1871.

16. Raymond MJ. The treatment of addiction by avversive conditioning with apomorphine. Behav Res Ther. 1963;1(2-4):287-91.

17. Hughes AJ, Lees AJ, Stern GM. The motor response to sequential apomorphine in parkinsonian fluctuations. J Neurol Neurosurg Psychiatry. 1991;358-60.

18. Stibe CMH, Kempster PA, Lees AJ, Stern GM. Subcutaneous apomorphine in Parkinsonian on-off oscillations. Lancet. 1988;331(8582):403-6.

19. Lemere F. Aversion treatment of alcoholism: some reminiscences. Addiction. 1987;82(3):257-8.

20. Mulhall JP. Sublingual apomorphine for the treatment of erectile dysfunction. Expert Opin Investig Drugs. 2002;11(2):295-302.

21. De Weill E. l'apomorphine dans certains troubles nerveux. Lyon Med. 1884;47:411-8.

22. Schwab RS, Amador LV, Lettvin JY. Apomorphine in Parkinson's disease. Trans Am Neurol Assoc. 1951;56:251-3.

23. Struppler A, Von Uexkull T. Studies of mechanism of action of apormorphine on Parkinson's tremor. Z Klin Med. 1953;152(1-2):46-57.

24. Cotzias GC. Levodopa in the treatment of Parkinsonism. JAMA. 1971;218(13):1903-8.

25. Yahr MD, Duvoisin RC, Schear MJ, Barrett RE, Hoehn MM. Treatment of parkinsonism with levodopa. Arch Neurol. 1969;21(4):343-54. 
26. Cotzias GC, Papavasiliou PS, Fehling C, Kaufman B, Mena I. Similarities between neurologic effects of L-dopa and of apomorphine. N Engl J Med. 1970;282(1):31-3.

27. Corsini GU, Del Zompo M, Gessa GL, Mangoni A. Therapeutic efficacy of apomorphine combined with an extracerebral inhibitor of dopamine receptors in Parkinson's disease. Lancet (London, England). 1979;1(8123):954-6.

28. Stibe C, Lees A, Stern G. Subcutaneous Infusion of apomorphine and lisuride in the treatment of parkinsonian on-off fluctuations. Lancet. 1987;329(8537):871.

29. Ernst AM, Smelik PG. Site of action of dopamine and apomorphine on compulsive gnawing behaviour in rats. Experientia. 1966;22(12):837-8.

30. Auffret M, Drapier S, Vérin M. Pharmacological insights into the use of apomorphine in parkinson's disease: clinical relevance. Clin Drug Investig. 2018;38(4):287-312.

31. Millan MJ, Maiofiss L, Cussac D, Audinot V, Boutin J-A, Newman-Tancredi A. Differential actions of antiparkinson agents at multiple classes of monoaminergic receptor. I. A multivariate analysis of the binding profiles of 14 drugs at 21 native and cloned human receptor subtypes. J Pharmacol Exp Ther. 2002;303(2):791-804.

32. Jenner P, Katzenschlager R. Apomorphine-pharmacological properties and clinical trials in Parkinson's disease. Park Relat Disord. 2016;33:S13-21.

33. LeWitt PA, Ondo WG, Van Lunen B, Bottini PB. Open-label study assessment of safety and adverse effects of subcutaneous apomorphine injections in treating 'off' episodes in advanced Parkinson disease. Clin Neuropharmacol. 2009;32(2):89-93.

34. Gancher ST, Nutt JG, Woodward WR. Absorption of apomorphine by various routes in parkinsonism. Mov Disord. 1991;6(3):212-6.

35. Nicolle E, Pollak P, Serre-Debeauvais F, Richard P, Gervason $\mathrm{CL}$, Broussolle E, et al. Pharmacokinetics of apomorphine in parkinsonian patients. Fundam Clin Pharmacol. 1993;7(5):245-52.

36. Manson AJ, Hanagasi H, Turner K, Patsalos PN, Carey P, Ratnaraj N, et al. Intravenous apomorphine therapy in Parkinson's disease: clinical and pharmacokinetic observations. Brain. 2001;124(Pt 2):331-40.

37. Haq IU, Lewitt PA, Fernandez HH. Apomorphine therapy in Parkinson's disease: a review. Expert Opin Pharmacother. 2007;8(16):2799-809.

38. Gancher ST, Woodward WR, Boucher SB, Nutt JG. Peripheral pharmacokinetics of apomorphine in humans. Ann Neurol. 1989;26(2):232-8.

39. Corboy DL, Wagner ML, Sage JI. Apomorphine for motor fluctuations and freezing in Parkinson's disease. Ann Pharmacother. 1995;29(3):282-8.

40. LeWitt PA. Subcutaneously administered apomorphine: pharmacokinetics and metabolism. Neurology. 2004;62(6 Suppl 4):S8-11.

41. Nomoto M, Kubo SI, Nagai M, Yamada T, Tamaoka A, Tsuboi $\mathrm{Y}$, et al. A randomized controlled trial of subcutaneous apomorphine for Parkinson disease: a repeat dose and pharmacokinetic study. Clin Neuropharmacol. 2015;38(6):241-7.

42. Isaacson S, Lew M, Ondo W, Hubble J, Clinch T, Pagan F. Apomorphine subcutaneous injection for the management of morning akinesia in Parkinson's disease. Mov Disord Clin Pract. 2016;4(1):78-83.

43. Gervason CL, Pollak PR, Limousin P, Perret JE. Reproducibility of motor effects induced by successive subcutaneous apomorphine injections in Parkinson's disease. Clin Neuropharmacol. 1993;16(2):113-9.
44. Hughes AJ, Bishop S, Stern GM, Lees AJ. The motor response to repeated apomorphine administration in Parkinson's disease. Clin Neuropharmacol. 1991;14(3):209-13.

45. Katzenschlager R, Poewe W, Rascol O, Trenkwalder C, Deuschl $\mathrm{G}$, Chaudhuri KR, et al. Apomorphine subcutaneous infusion in patients with Parkinson's disease with persistent motor fluctuations (TOLEDO): a multicentre, double-blind, randomised, placebo-controlled trial. Lancet Neurol. 2018;17(9):749-59.

46. Frankel JP, Lees AJ, Kempster PA, Stern GM. Subcutaneous apomorphine in the treatment of Parkinson's disease. J Neurol Neurosurg Psychiatry. 1990;53(2):96-101.

47. Pietz K, Hagell P, Odin P. Subcutaneous apomorphine in late stage Parkinson's disease: a long term follow up. J Neurol Neurosurg Psychiatry. 1998;65(5):709-16.

48. Wenning GK1, Bösch S, Luginger E, Wagner M PW. Effects of long-term, continuous subcutaneous apomorphine infusions on motor complications in advanced Parkinson's disease. PubMed NCBI. Adv Neurol. 1999;(80):545-8.

49. Merello M, Pikielny R, Cammarota A, Leiguarda R. Comparison of subcutaneous apomorphine versus dispersible madopar latency and effect duration in Parkinson's disease patients. Clin Neuropharmacol. 2006;20(2):165-7.

50. Dewey RB, Maraganore D, Ahlskog JE, Matsumoto J. A doubleblind, placebo-controlled study of intranasal apomorphine spray as a rescue agent for off-states in Parkinson's disease. Mov Disord. 1998;13(5):782-7.

51. Antonini A. Apomorphine and levodopa infusion therapies for advanced Parkinson's disease. J Mov Disord. 2009;2(1):4-9.

52. Anthony J, Spears J, Van Lunen B. Implications of motor fluctuations in Parkinson's disease patients on chronic therapy (IMPACT): results from an observational registry. Mov Disord. 2005;20:S146.

53. Lees A. Dopamine agonists in Parkinson's disease: a look at apomorphine. Fundam Clin Pharmacol. 1993;7(3-4):121-8.

54. Dewey RB Jr, Hutton JT, LeWitt PA, Factor SA. A Randomized, double-blind, placebo-controlled trial of subcutaneously injected apomorphine for Parkinsonian off-state events. Arch Neurol. 2003;58(9):1385.

55. Gunzler SA, Koudelka C, Carlson NE, Pavel M, Nutt JG. Effect of low concentrations of apomorphine on parkinsonism in a randomized, placebo-controlled, crossover study. Arch Neurol. 2008;65(2):193-8.

56. Pahwa R, Koller WC, Trosch RM, Sherry JH. Subcutaneous apomorphine in patients with advanced Parkinson's disease: a dose-escalation study with randomized, double-blind, placebocontrolled crossover evaluation of a single dose. J Neurol Sci. 2007;258(1-2):137-43.

57. Canadian Agency for Drugs. Clinical Review Report: Apomorphine (Movapo): (Paladin Labs Inc.): Indication: The acute, intermittent treatment of hypomobility "off" episodes ("endof-dose wearing off" and unpredictable "on/off" episodes) in patients with advanced Parkinson's disease. CADTH Common Drug Reviews. 2018.

58. Antonini A, Jenner P. Apomorphine infusion in advanced Parkinson disease. Nat Rev Neurol. 2018;14(12):693-4.

59. Antonini A, Nitu B. Apomorphine and levodopa infusion for motor fluctuations and dyskinesia in advanced Parkinson disease. J Neural Transm. 2018;125(8):1131-5.

60. Sesar Á, Fernández-Pajarín G, Ares B, Relova JL, Arán E, Rivas MT, et al. Continuous subcutaneous apomorphine in advanced Parkinson's disease patients treated with deep brain stimulation. J Neurol. 2019;266(3):659-66.

61. Borgemeester RWK, van Laar T. Continuous subcutaneous apomorphine infusion in Parkinson's disease patients with cognitive 
dysfunction: a retrospective long-term follow-up study. Park Relat Disord. 2017;45:33-8.

62. García Ruiz PJ, Sesar Ignacio Á, Ares Pensado B, Castro García A, Alonso Frech F, Álvarez López M, et al. Efficacy of long-term continuous subcutaneous apomorphine infusion in advanced Parkinson's disease with motor fluctuations: a multicenter study. Mov Disord. 2008;23(8):1130-6.

63. Borgemeester RWK, Drent M, van Laar T. Motor and non-motor outcomes of continuous apomorphine infusion in 125 Parkinson's disease patients. Park Relat Disord. 2016;23:17-22.

64. Todorova A, Ray Chaudhuri K. Subcutaneous, intranasal and transdermal dopamine agonists in the management of Parkinson's disease. Park Dis Curr Futur Ther Clin Trials. 2016;48-62.

65. Katzenschlager R, Hughes A, Evans A, Manson AJ, Hoffman M, Swinn L, et al. Continuous subcutaneous apomorphine therapy improves dyskinesias in Parkinson's disease: a prospective study using single-dose challenges. Mov Disord. 2005;20(2):151-7.

66. Olanow CW, Kieburtz K, Odin P, Espay AJ, Standaert DG, Fernandez $\mathrm{HH}$, et al. Continuous intrajejunal infusion of levodopa-carbidopa intestinal gel for patients with advanced Parkinson's disease: a randomised, controlled, double-blind, double-dummy study. Lancet Neurol. 2014;13(2):141-9.

67. Manson AJ, Turner K, Lees AJ. Apomorphine monotherapy in the treatment of refractory motor complications of Parkinson's disease: long-term follow-up study of 64 patients. Mov Disord. 2002;17(6):1235-41.

68. Katunina E, Titova N. The Epidemiology of Nonmotor Symptoms in Parkinson's Disease (Cohort and Other Studies). In: International review of neurobiology. 2017. pp. 91-110.

69. Martinez-Martin P, Reddy P, Antonini A, Henriksen T, Katzenschlager R, Odin P, et al. Chronic subcutaneous infusion therapy with apomorphine in advanced Parkinson's disease compared to conventional therapy: a real life study of non motor effect. J Parkinsons Dis. 2011;1(2):197-203.

70. Martinez-Martin P, Reddy P, Katzenschlager R, Antonini A, Todorova A, Odin P, et al. EuroInf: a multicenter comparative observational study of apomorphine and levodopa infusion in Parkinson's disease. Mov Disord. 2015;30(4):510-6.

71. Borgemeester RWK, Lees AJ, van Laar T. Parkinson's disease, visual hallucinations and apomorphine: a review of the available evidence. Park Relat Disord. 2016;27:35-40.

72. Rosa-Grilo M, Qamar MA, Evans A, Chaudhuri KR. The efficacy of apomorphine-a non-motor perspective. Park Relat Disord. 2016;33:S28-35.

73. Ellis C, Lemmens G, Parkes JD, Abbott RJ, Pye IF, Leigh PN, et al. Use of apomorphine in Parkinsonian patients with neuropsychiatric complications to oral treatment. Park Relat Disord. 1997;3(2):103-7.

74. Moore TJ, Glenmullen J, Mattison DR. Reports of pathological gambling, hypersexuality, and compulsive shopping associated with dopamine receptor agonist drugs. JAMA Intern Med. 2014; 174(12): 1930.

75. Barbosa P, Lees AJ, Magee C, Djamshidian A, Warner TT. A retrospective evaluation of the frequency of impulsive compulsive behaviors in parkinson's disease patients treated with continuous waking day apomorphine pumps. Mov Disord Clin Pract. 2016;4(3):323-8.

76. Samuel M, Rodriguez-Oroz M, Antonini A, Brotchie J, Ray Chaudhuri K, Brown R, et al. Impulse control disorders in parkinson's disease: management, controversies, and potential approaches HHS public access. Mov Disord. 2015;30(2):150-9.
77. Himeno E, Ohyagi Y, Ma L, Nakamura N, Miyoshi K, Sakae $\mathrm{N}$, et al. Apomorphine treatment in Alzheimer mice promoting amyloid- $\beta$ degradation. Ann Neurol. 2011;69(2):248-56.

78. Yarnall AJ, Lashley T, Ling H, Lees AJ, Coleman SY, O'Sullivan SS, et al. Apomorphine: a potential modifier of amyloid deposition in Parkinson's disease? Mov Disord. 2016;31(5):668-75.

79. Deleu D, Hanssens Y, Northway MG. Subcutaneous apomorphine: an evidence-based review of its use in Parkinson's disease. Drugs Aging. 2004;21(11):687-709.

80. Loewe R, Püspök-Schwarz M, Petzelbauer P. Apomorphin-pigmentierung. Der Hautarzt. 2003;54(1):58-63.

81. Acland KM, Churchyard A, Fletcher CL, Turner K, Lees A, Dowd PM. Panniculitis in association with apomorphine infusion. Br J Dermatol. 1998;138(3):480-2.

82. Skorvanek M, Bhatia KP. The skin and Parkinson's disease: review of clinical, diagnostic, and therapeutic issues. Mov Disord Clin Pract. 2017;4(1):21-31.

83. Barbosa P, Lees AJ, Magee C, Djamshidian A, Warner TT. A retrospective evaluation of the frequency of impulsive compulsive behaviors in Parkinson's disease patients treated with continuous waking day apomorphine pumps. Mov Disord Clin Pract. 2017;4(3):323-8.

84. A. Todorova, A. Martin, D. Okai, M.Samuel, R. Brown, A. David KRC. Assessment of impulse control disorders in Parkinson's patients with infusion therapies: a single centre experience. Mov Disord. 2013;28(Suppl. 1):366.

85. Venegas Pérez B, Arquero Portero T, Sánchez Fernández MS, Feliz Feliz C, Del Val Fernández J, García-Ruiz PJ. Apomorphine-induced immune hemolytic anemia. Mov Disord Clin Pract. 2017;4(1):145-7.

86. Renoux C, Dell'Aniello S, Khairy P, Marras C, Bugden S, Turin $\mathrm{TC}$, et al. Ventricular tachyarrhythmia and sudden cardiac death with domperidone use in Parkinson's disease. Br J Clin Pharmacol. 2016;461-472.

87. Yüksel K, Tuğlular I. Critical review of European Medicines Agency (EMA) assessment report and related literature on domperidone. Int J Clin Pharm. 2019;41(2):387-90.

88. Bhidayasiri R, Chaudhuri KR, LeWitt P, Martin A, Boonpang $\mathrm{K}$, van Laar T. Effective delivery of apomorphine in the management of Parkinson disease. Clin Neuropharmacol. 2015;38(3):1.

89. Bhidayasiri R, Sringean J, Anan C, Boonpang K, Thanawattano C, Ray Chaudhuri K. Quantitative demonstration of the efficacy of night-time apomorphine infusion to treat nocturnal hypokinesia in Parkinson's disease using wearable sensors. Park Relat Disord. 2016;33:S36-41.

90. Trenkwalder C, Chaudhuri KR, García Ruiz PJ, LeWitt P, Katzenschlager R, Sixel-Döring F, et al. Expert Consensus Group report on the use of apomorphine in the treatment of Parkinson's disease - clinical practice recommendations. Park Relat Disord. 2015;21(9):1023-30.

91. Grosset KA, Malek N, Morgan F, Grosset DG. Phase IIa randomized double-blind, placebo-controlled study of inhaled apomorphine as acute challenge for rescuing 'off' periods in patients with established Parkinson's disease. Eur J Neurol. 2013;20(11):1445-50.

92. Grosset KA, Malek N, Morgan F, Grosset DG. Inhaled dry powder apomorphine (VR040) for'off' periods in Parkinson's disease: an in-clinic double-blind dose ranging study. Acta Neurol Scand. 2013;128(3):166-71.

93. Grosset KA, Malek N, Morgan F, Grosset DG. Inhaled apomorphine in patients with 'on-off' fluctuations: a randomized, double-blind, placebo-controlled, clinic and home based, parallelgroup study. J Parkinsons Dis. 2013;3(1):31-7.

94. Borkar N, Andersson DR, Yang M, Müllertz A, Holm R, Mu H. Efficacy of oral lipid-based formulations of apomorphine and its 
diester in a Parkinson's disease rat model. J Pharm Pharmacol. 2017;69(9):1110-5.

95. Argiolas A, Hedlund H. The pharmacology and clinical pharmacokinetics of apomorphine SL. BJU Int Suppl. 2001;88(3):18-21.

96. Fernandez HH, Isaacson S, Espay AJ, Pahwa R, Truong D, Pappert E, et al. Safety of sublingual apomorphine film (APL130277) for the treatment of OFF-episodes in subjects with Parkinson's disease: preliminary results from the Phase- 3 study dose titration phase. Parkinsonism Relat Disord. 2018;46:e82.

97. Lees AJ, Montastruc JL, Turjanski N, Rascol O, Kleedorfer B, Peyro Saint-Paul H, et al. Sublingual apomorphine and Parkinson's disease. J Neurol Neurosurg Psychiatry. 1989;52(12):1440.

98. Hauser RA, Olanow CW, Dzyngel B, Bilbault T, Shill H, Isaacson S, et al. Sublingual apomorphine (APL-130277) for the acute conversion of OFF to ON in Parkinson's disease. Mov Disord. 2016;31(9):1366-72.

99. Factor SA, Isaacson S, Hauser RA et al. Efficacy and safety of apomorphine sublingual film for the treatment of 'OFF' episodes in patients with Parkinson's disease: phase 3, double blind placebo-controlled trail. 2019.

100. Shaltiel-Karyo R, Tsarfati Y, Zawoznik E, Weinstock I, Nemas M, Rubinski A, Schiffenbauer Y, Nyska A, Yacoby-Zeevi O. ND0701: A novel safe concentrated apomorphine formulation for continuous subcutaneous administration via a patch pump (P4.006). Neurology. 2107. 88 (16 Sup):P4.006.

101. Ramot Y, Nyska A, Adar L, Durlach C, Fishelovitch D, Sacco G, et al. ND0701, A novel formulation of apomorphine for subcutaneous infusion, in comparison to a commercial apomorphine formulation: 28-day pharmacokinetic study in minipigs and a phase I study in healthy volunteers to assess the safety, tolerability, npharmacokinetics and relative bioavailability. CNS Drugs. 2018;32(5):443-54.

102. Poewe W, Kleedorfer B, Gerstenbrand F, Oertel WH. Die Behandlung von Parkinsonpatienten mit L-Dopa-Wirkungsfluktuation mittels subkutanen Apomorphingaben. Aktuelle Neurol. 1989;16(3):73-7.

103. Poewe W, Kleedorfer B, Wagner M, Benke T, Gasser T, Oertel W. Side-effects of subcutaneous apomorphine in Parkinson's disease. Lancet. 1989;333(8646):1084-5.

104. Hughes AJ, Bishop S, Kleedorfer B, Turjanski N, Fernandez W, Lees AJ, et al. Subcutaneous apomorphine in parkinson's disease: response to chronic administration for up to five years. Mov Disord. 1993;8(2):165-70.

105. Esteban Muñoz J, Martí MJ, Marín C, Tolosa E. Long-term treatment with intermitent intranasal or subcutaneous apormorphine in patients with levodopa-related motor fluctuations. Clin Neuropharmacol. 1997;20(3):245-52.

106. Van Laar T, Jansen ENH, Essink A, Neef C, S. O, van Laar T, et al. A double-blind study of the efficacy of apomorphine and its assessment in 'off'-periods in Parkinson's disease. Clin Neurol Neurosurg. 1993;95(3):231-235.

107. Ostergaard L, Werdelin L, Odin P, Lindvall O, Dupont E, Christensen $\mathrm{PB}$, et al. Pen injected apomorphine against off phenomena in late Parkinson's disease: a double blind, placebo controlled study. J Neurol Neurosurg Psychiatry. 1995;58(6):681-7.

108. Pfeiffer RF, Gutmann L, Hull KL, Bottini PB, Sherry JH. Continued efficacy and safety of subcutaneous apomorphine in patients with advanced Parkinson's disease. Park Relat Disord. 2007;13(2):93-100.

109. Hattori N, Nomoto M, Kimura T, Kikuchi S, Enomoto H, Yoshizawa K, et al. Sustained efficacy of apomorphine in Japanese patients with advanced Parkinson's disease. Park Relat Disord. 2014;20(8):819-23.

110. PharmaPendium, Post-marketing reports (AERS) for apomorphine hydrochloride and cardiac disorders. https://www.pharm apendium.com/postmarket.do?initial.drug $\% 5 \mathrm{~B} 0 \% 5 \mathrm{D}=\mathrm{Apomo}$ rphine + Hydrochloride $\&$ strcture $=$ false $\&$ multi View.statE ntity Type $=$ EFFEC T \& chemi stry $=$ false $\&$ initi al.effec t\&5B0\%5D=Cardiac+disorders\&multiView.entityType=DRUG.

111. Watanabe Y, Nakamura Y, Cao X, Ohara H, Yamazaki Y, Murayama N, Sugiyama Y, Izumi-Nakaseko H, Ando K, Yamazaki $\mathrm{H}$, Sugiyama A. Intravenous Administration of Apomorphine Does NOT Induce Long QT Syndrome: Experimental Evidence from Canine Models. Basic Clin Pharmacol Toxicol. 2015;116(6):468-75.

112. Stocchi F, Vacca L, De Pandis MF, Barbato L, Valente M, Ruggieri S. Subcutaneous continuous apomorphine infusion in fluctuating patients with Parkinson's disease: long-term results. Neurol Sci. 2001;22(1):93-4.

113. Tyne HL, Parsons J, Sinnott A, Fox SH, Fletcher NA, Steiger MJ. A 10 year retrospective audit of long-term apomorphine use in Parkinson's disease. J Neurol. 2004;251(11):1370-4.

114. Drapier S, Gillioz A-N, Leray E, Péron J, Rouaud T, Marchand A, Vérin M. Apomorphine infusion in advanced Parkinson's patients with subthalamic stimulation contraindications. Parkinsonism Relat Disord. 2012;18(1):40-4.

115. Kimber TE, Fang J, Huddy LJ, Thompson PD. Long-term adherence to apomorphine infusion in patients with Parkinson disease: a 10-year observational study. Int Med J. 2017;47(5):570-3.

116. Rambour M, Moreau C, Salleron J, Devos D, Kreisler A, Mutez E, Simonin C, Annic A, Dujardin K, Destee A, Defebvre L. Le traitement par apomorphine en perfusion continue sous-cutanée dans la maladie de Parkinson: analyse rétrospective d'une série de 81 patients. Revue Neurologique. 2014;170(3):205-15.

117. Drapier S, Eusebio A, Degos B, Vérin M, Durif F, Azulay JP, Viallet F, Rouaud T, Moreau C, Defebvre L, Fraix V, Tranchant C, Andre K, Courbon CB, Roze E, Devos D. Quality of life in Parkinson's disease improved by apomorphine pump: the OPTIPUMP cohort study. J Neurol. 2016;263(6):1111-9.

118. Sesar A, Fernández-Pajarín G, Ares B, Rivas MT, Castro A. Continuous subcutaneous apomorphine infusion inadvanced Parkinson's disease: 10-year experience with 230 patients. J Neurol. 2017;264(5):946-54. 